\title{
Anti-inflammation and antimalarial profile of 5-pyridin-2-yl-1H-[1,2,4]triazole-3-carboxylic acid ethyl ester as a low molecular intermediate for hybrid drug synthesis
}

\author{
Francois Eya'ane Meva ${ }^{1,2,3}$ (D) . Timothy J. Prior ${ }^{2}$. \\ David J. Evans ${ }^{2,7}$. Sachin Shah ${ }^{2,7}$. Cynthia Fake Tamngwa ${ }^{1}$. \\ Herschelle Guyenne Lagrange Belengue ${ }^{1} \cdot$ Roland Emmanuel Mang $^{4}$. \\ Justin Munro ${ }^{5,6}$ - Tarrick Qahash ${ }^{3,6}$. Manuel Llinás ${ }^{3,5,6}$
}

Received: 3 July 2021 / Accepted: 13 October 2021 / Published online: 28 October 2021

(c) Springer Nature B.V. 2021

\begin{abstract}
A novel 1,2,4-triazole intermediate 5-pyridin-2-yl-1H-[1,2,4]triazole-3-carboxylic acid ethyl ester was prepared by the reaction of N'-aminopiridyne-2-carboximidamine and an excess monoethyl oxalyl chloride and screened for biological activities. The compound was structurally characterized by nuclear magnetic resonance spectroscopy, elemental analysis, infrared spectroscopy, and single-crystal X-ray diffraction. Bioassays indicated that the compound exhibits potent anti-inflammation activity in vitro. An egg albumin denaturation assay to assess the anti-inflammatory effect of the synthesized compound showed a significant inhibition of protein with a maximum inhibition of $71.1 \%$ at the highest tested concentration $(1000 \mu \mathrm{g} / \mathrm{mL})$ compared to $81.3 \%$ for Aspirin as standard drug. The antimalarial activity on the 3D7 P. falciparum strain was determined to be $\mathrm{IC}_{50} 176 \mu \mathrm{M}$ and was obtained prior to connection with pharmacophoric groups.
\end{abstract}

Francois Eya' ane Meva

francois.eyaane@fulbrightmail.org

1 Department of Pharmaceutical Sciences, Faculty of Medicine and Pharmaceutical Sciences, University of Douala, PO Box 2701, Douala, Cameroon

2 Department of Chemistry and Biochemistry, University of Hull, Hull HU6 7RX, UK

3 Department of Biochemistry and Molecular Biology, The Pennsylvania State University, State College, PA 16803, USA

4 Department of Chemistry, University of Douala, PO Box 24157, Douala, Cameroon

5 Department of Chemistry, The Pennsylvania State University, State College, PA 16803, USA

6 Huck Center for Malaria Research, The Pennsylvania State University, State College, PA 16803, USA

7 Present Address: John Innes Centre, Norwich Research Park, Norwich NR4 7UH, UK 
Keywords 1.2.4-triazole $\cdot$ Synthesis $\cdot$ Structure $\cdot$ Anti-inflammation $\cdot$ Antimalarial

\section{Introduction}

The spread of drug resistance is continuously challenging global health and commands the development of new therapeutics with high bioactivity and safety. Nature has provided many therapeutic models containing heterocycle subunits that are found in vitamins, hormones, antibiotics, and alkaloids [1]. Transposition, derivatization and hybrid drug design is an excellent way to reduce the cost of manufacturing involved and to enhance drug development to thwart resistance. Triazoles are the isosters of imidazoles in which the carbon atom of imidazole is isosterically replaced by nitrogen [2]. Triazoles are five-membered rings which contain two carbons, three nitrogen atoms and occur in two possible isomeric forms, 1,2,3-triazoles and 1,2,4-triazoles [3]. 1,2,4-triazoles in particular are very interesting due to their stability and ability to bind to a wide variety of enzymes and receptors [4]. They also exhibit a broad spectrum of pharmacological action [5]. Their uses in biological and materials chemistry have been extensively reviewed over the years [6-8]. This motif is an integral part of a variety of drugs such as fluconazole, estazolam, trapidil, anastrozole, letrozole, and ribavirin which has recently received a lot of attention due to potential antiviral activity in the context of COVID-19 $[9,10]$.

Various synthetic routes have been described to synthesize 3,5-disubstituted 1,2,4-triazole derivatives. The combination of amide and acyl hydrazide is generally referred to as the Pellizzari Reaction (developed in 1894) and can be used to obtain 3,5-diphenyl-1,2,4-triazole at $140{ }^{\circ} \mathrm{C}$ [11]. A recent synthetic example is a procedure based on zinc(II)-catalysed acyl hydrazide-dialkylcyanamide coupling, which allows the utilization of cyanamides bearing donor alkylsubstituents and gives 3-dialkylamino-1,2,4-triazoles such as 3-dimethylamino-5-phenyl-1,2,4-triazole under mild conditions and in high yields [12]. Another example is the intramolecular ring closure of acyl-amidrazonzes, using tosyl-amidrazone treated with acetyl chloride to obtain 5-methyl-3-(2',3',4',6'-tetra-O-benzoyl-b-D-glucopyranosyl)1-tosyl-1,2,4-triazole [13]. Diketoesters react with hydrazine in most routes to obtain pyrazoles, and monoethyl oxalyl chloride has been used in various ways to produce a five-ring cyclisation $[14,15]$. Chen and co-workers used zirconacyclopentene in the presence of $\mathrm{CuCl}$ to obtain cyclopentenone [16]. Furstner and co-workers treated the ethyl ester adducts with trichlorotitanium and zinc in DME to form an indole derivative [17] and Bradley and co-workers treated ethyl ester adducts with Lawesson's reagent to obtain thiadiazole derivatives [18]. Most existing methods suffer from multistep synthetic procedures, inferior regioselectivity, narrow substrate scope, and limited functional group tolerance [19]. Haggam reported the synthesis of 1,2-bis-(4-amino-5-mercapto-4H-1,2,4-triazol-3-yl)benzene via the dehydrative cyclisation reaction of phthalic acid with thiocarbohydrazide in dry pyridine heated under reflux for $4 \mathrm{~h}$ [20]. He described recently the synthesis of 1,2-bis-(4-amino5-mercapto-1,2,4-triazol-3-yl)-ethane and 1,2-bis-(4-amino-5-mercapto-4H-1,2,4triazol-3-yl)-ethan-1-ol from a mixture of succinic acid, respectively, dl-malic acid with thiocarbohydrazide under microwave irradiation and temperature [21, 22]. The 

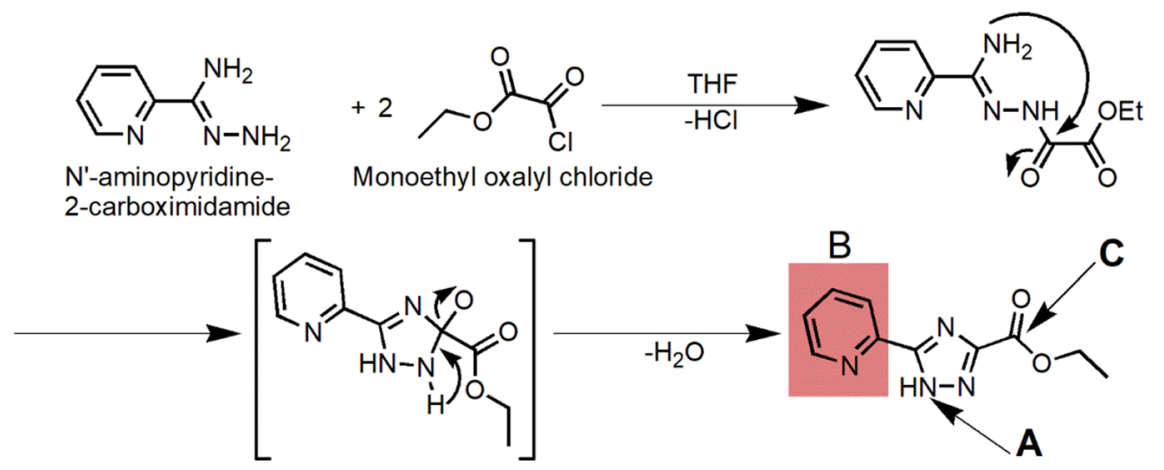

5-pyridin-2-yl-1H-[1,2,4]triazole-3carboxylic acid ethyl ester

Scheme 1 Synthesis of 5-pyridin-2-yl-1H-[1,2,4]triazole-3-carboxylic acid ethyl ester with indications of substitution possibilities of further pharmacophoric groups at positions A-C

used protocols provided higher yields and shorter reaction times in comparison with thermal procedures. Shahnavaz and coworkers performed the preparation of a series of 5-amino-7-aryl-4,7-dihydro-[1,2,4]triazolo[1,5-a]pyrimidine-6-carboxylates using the catalytic efficiency of an ionic liquid derivative $\left[\mathrm{TMDPH}_{2}\right]^{2+}\left[\mathrm{SO}_{4}\right]^{2-}(\mathrm{TM}$ $\mathrm{DP}=4,4^{\prime}$-trimethylenedipiperidine) through condensation of 3-amino-1,2,4-triazole, various substituted aromatic aldehydes, and ethyl cyanoacetate in ethanol/water at room temperature [23]. Rezki and coworkers obtained 5-(4-fluorophenyl)-2,4-dihydro-1,2,4-triazole-3-thione and 4-ethyl-5-(4-fluorophenyl)-2,4-dihydro-1,2,4-triazole-3-thione, respectively, by reacting 4-fluorobenzoylchloride with thiosemicarbazide, respectively, ethylisothiocyanate, followed by cyclization in basic medium $(10 \% \mathrm{NaOH})$. [24] Namratha and coworkers performed the cyclodehydration of $\mathrm{N}$-[4-(4-nitrophenoxy)phenyl]-2-(phenylcarbonyl)hydrazinecarbothioamide in basic medium to afford 4[4-(4-nitrophenoxy)phenyl]-5-substituted-2H-1,2,4-triazole3-thiones [25]. In order to obtain ethyl 5-benzyl-1-(pyridin-3-yl)-1H-1,2,4-triazole3-carboxylate, Jaisankar and coworkers treated ethyl 2-amino-2-[2-(3-pyridyl) hydrazono]acetate with phenylacetyl chloride in toluene at $0{ }^{\circ} \mathrm{C}$. After refluxing the mixture for $12 \mathrm{~h}$ and solvent evaporation, the residue was dissolved in $\mathrm{CH}_{2} \mathrm{Cl}_{2}$ and washed successively with $1 \mathrm{~N} \mathrm{HCl}, 10 \% \mathrm{NaHCO}_{3}$, and brine to be isolated as a brown gummy solid [26]. Pertinent to the development of new 1,2,4-triazoles, here we present a one-pot approach using ethyl oxalyl chloride and the structural characterisation of a promising triazole-base anti-inflammatory agent.

\section{Results and discussion}

\section{Synthesis and characterization}

The target compound is obtained by refluxing N'-aminopyridine-2-carboximidamide in an excess of monoethyl oxalyl chloride in tetrahydrofuran (see Scheme 1) 
[27]. The ethyl ester adduct undergoes intramolecular cyclization to form the triazole ring. The target molecule bears possibilities for further synthetic reactions to yield hybrid molecules with enhanced properties. The structure of the product has been verified by nuclear magnetic resonance spectroscopy (NMR) and infrared (IR) spectroscopy. Solvent diffusion of ether into a methanolic solution of the product yielded white crystals that have been examined by X-ray diffraction.

\section{Spectroscopic studies}

The ${ }^{1} \mathrm{H}-\mathrm{NMR}$ (Fig. 1) spectrum of the synthesized compound presents four signals between 7.5 and $9.0 \mathrm{ppm}$, each with integration one consistent with the pyridine ring protons. The quartet at $4.3 \mathrm{ppm}$, with integration two, is consistent with the $-\mathrm{CH}_{2}-$ group and the triplet at $1.3 \mathrm{ppm}$, with integration three, is consistent with the $-\mathrm{CH}_{3}$ group: both are consistent with an ethyl ester [28]. The proton linked to the nitrogen appears above $13 \mathrm{ppm}$ and is not shown due to the measurement range 0-12 ppm. The ${ }^{13} \mathrm{C}$-NMR (Fig. 1) spectrum of the compound exhibited ten peaks corresponding to the number of carbons of the 1,2,4-triazole. The signal at $12 \mathrm{ppm}$ corresponds to the $-\mathrm{CH}_{3}$ group, the signal at $62 \mathrm{ppm}$ corresponds to the $-\mathrm{CH}_{2}$ - group and the carbonyl carbon $\mathrm{C}=\mathrm{O}$ is found at $160 \mathrm{ppm}$. The FT-IR spectrum (Fig. 2) of the 1,2,4-triazole showed characteristic absorption peaks at $2600-3100 \mathrm{~cm}^{-1}$ due to $\mathrm{C}-\mathrm{H}$ aromatic vibrations. Peaks at 1541 and $1474 \mathrm{~cm}^{-1}$ were assigned to $\mathrm{C}=\mathrm{C}$ stretching for aromatic groups. The vibration peak for $\mathrm{N}=\mathrm{N}$ is observed at $1541 \mathrm{~cm}^{-1}$. Esters have a characteristic pattern of three intense peaks at 1742,1222 , and $1037 \mathrm{~cm}^{-1}$ from the $\mathrm{C}=\mathrm{O}$ and two $\mathrm{C}-\mathrm{O}$ stretches. Vibrations between $3300-3500 \mathrm{~cm}^{-1}$ can be attributed to secondary amine $\mathrm{N}-\mathrm{H}$. All other carbon signals correspond to aromatic rings. The mass spectrometry data (Fig. 3) exhibited a parent peak signal at $\mathrm{m} / \mathrm{z} 218$ consistent with the assigned molecular formula and consistent with elemental analysis (Table 1).

\section{Description of the crystal structure}

Single-crystal X-ray diffraction confirmed the structure of 5-pyridin-2-yl$1 \mathrm{H}-[1,2,4]$ triazole-3-carboxylic acid ethyl ester. Crystal structure and refinement information for 5-pyridin-2-yl-1H-[1,2,4]triazole-3-carboxylic acid ethyl ester are shown in Table 2. The refinement converged with final quality of fit $\mathrm{R} 1=0.0322$ and $w R\left(F^{2}\right)=0.0609$. 5-pyridin-2-yl-1H-[1,2,4]triazole-3-carboxylic acid ethyl ester crystallizes in the centric space group $P 2{ }_{1} / c$ with two independent molecules in the asymmetric unit that are in extremely similar molecular conformations as shown in Fig. 4. In each molecule the five-membered ring and the six-membered ring are very close to being co-planar; the rms deviation of atoms in the ring containing C6 from the mean plane of the six-ring containing N1 is $0.09 \AA$ and the equivalent deviation for the second independent molecule is $0.06 \AA$. The torsion angles N1-C5-C6-N2 and N5-C15-C16-N6 are 5.0(2) and 4.1(2) ${ }^{\circ}$, respectively. Similarly, there is no significant difference in the orientation of the ester groups with respect to the rest of the molecule. The two classical hydrogen bonds within 

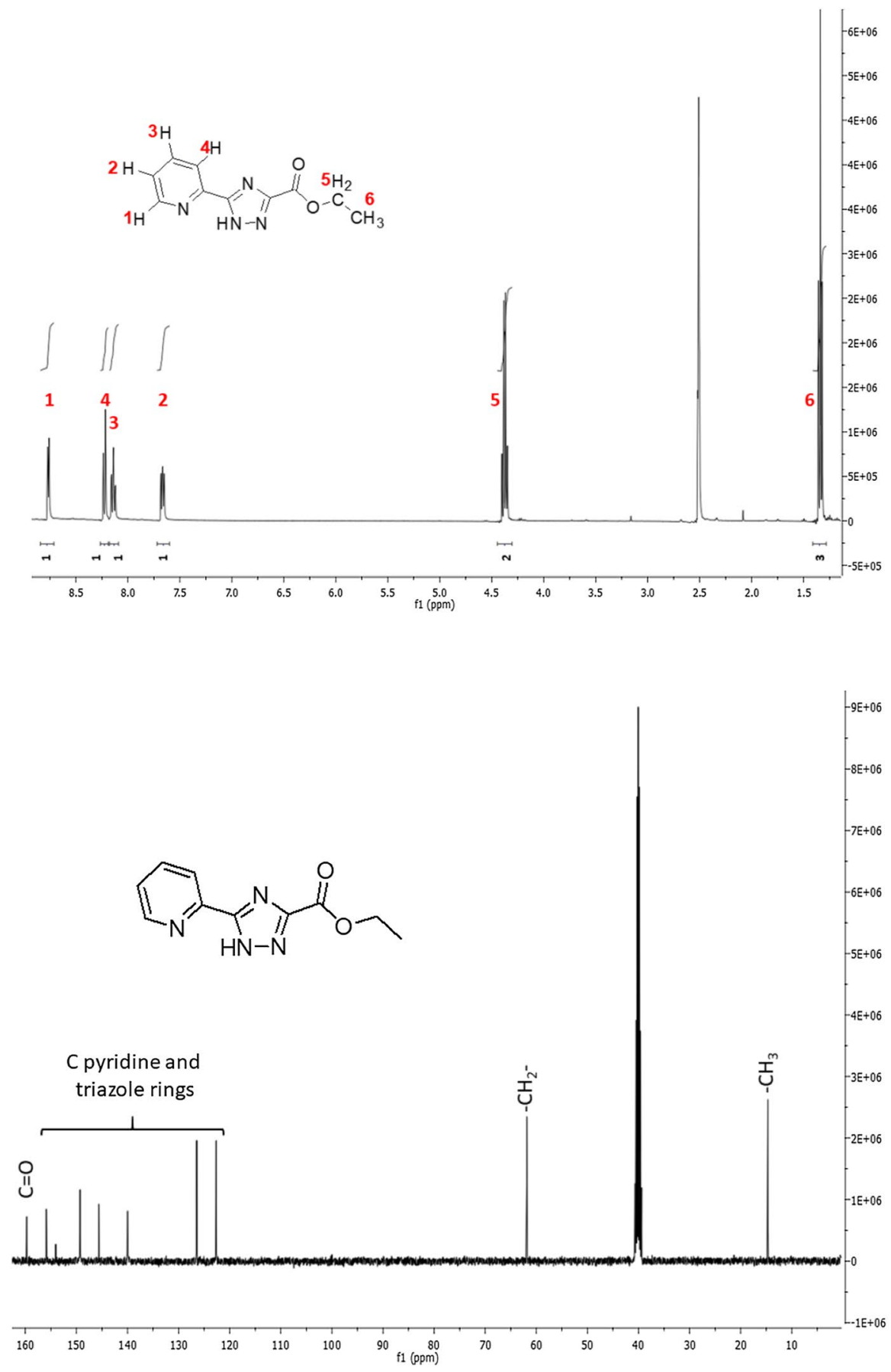

Fig. $1{ }^{13} \mathrm{C}$ and ${ }^{1} \mathrm{H}$ NMR spectra of 5-Pyridin-2-yl-1H-[1,2,4]triazole-3-carboxylic acid ethyl ester 


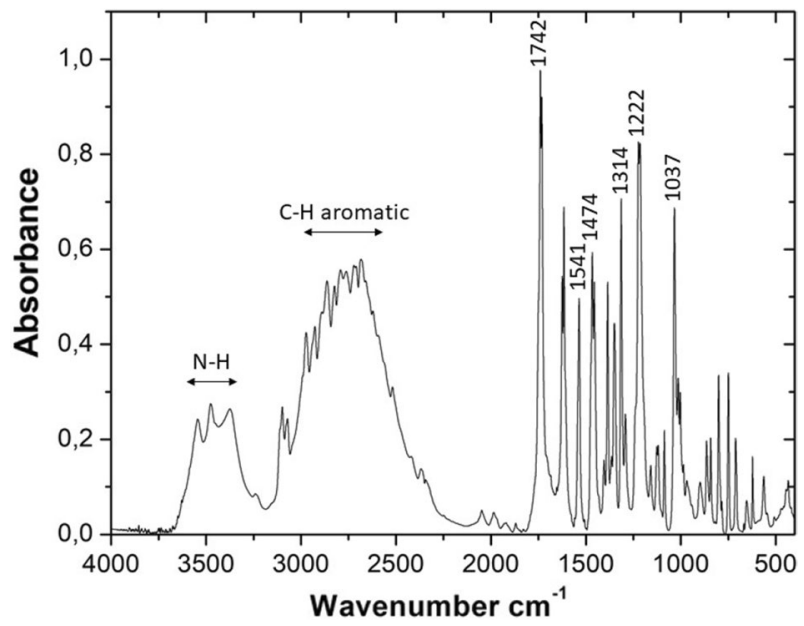

Fig. 2 FT-IR spectrum of synthesized 5-Pyridin-2-yl-1H-[1,2,4]triazole-3-carboxylic acid ethyl ester

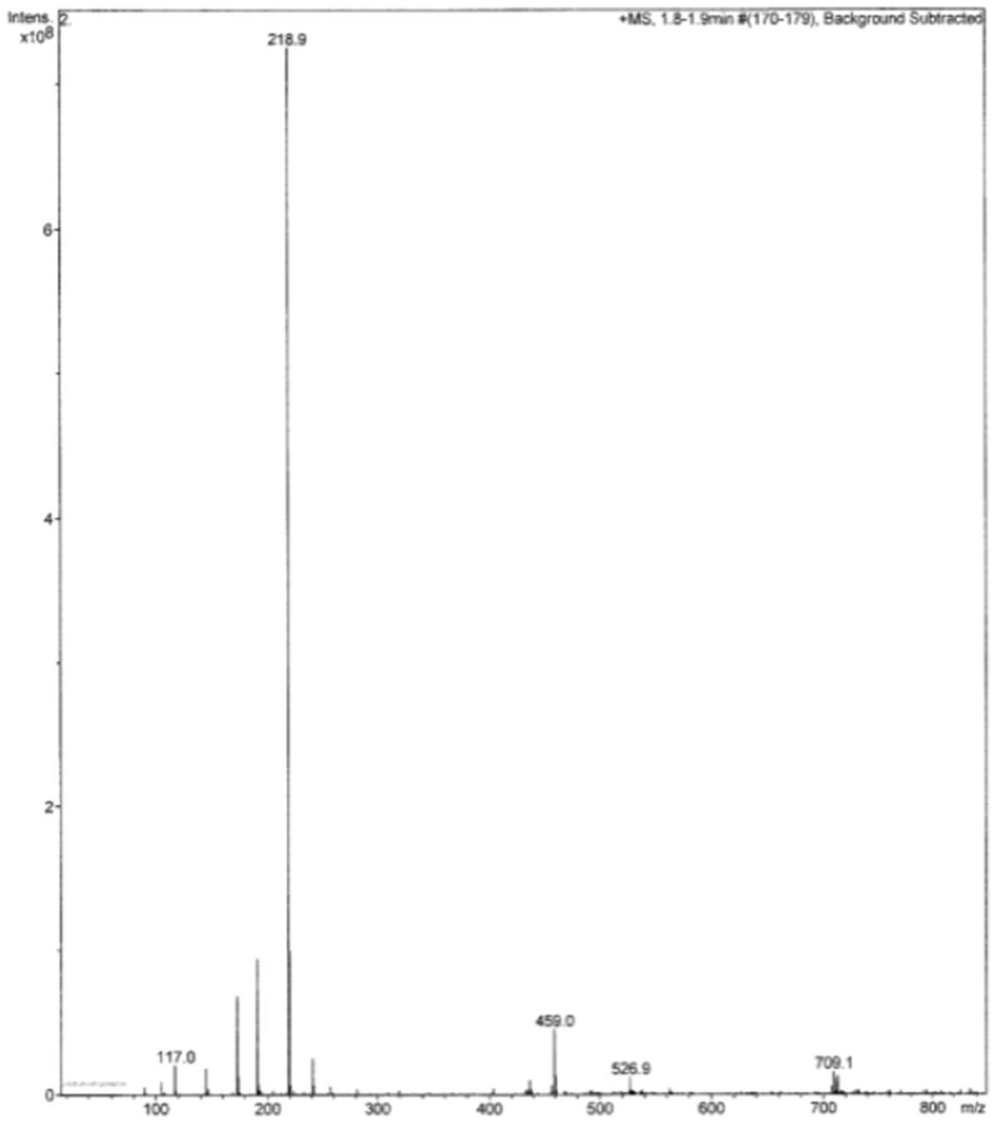

Fig. 3 Mass spectroscopy fingerprint of 5-Pyridin-2-yl-1H-[1,2,4]triazole-3-carboxylic acid ethyl ester 
Table 1 Elemental analysis of 5-Pyridin-2-yl-1H-[1,2,4] triazole-3-carboxylic acid ethyl ester

\begin{tabular}{llll}
\hline & $\mathrm{C}$ & $\mathrm{N}$ & $\mathrm{O}$ \\
\hline Calculated \% & 55.04 & 25.68 & 14.66 \\
Obtained \% & 55.86 & 25.01 & 15.10 \\
\hline
\end{tabular}

Table 2 Crystal structure and refinement information for 5-pyridin-2-yl-1H-[1,2,4]triazole-3-carboxylic acid ethyl ester

\begin{tabular}{|c|c|}
\hline Empirical formula & $\mathrm{C} 10 \mathrm{H} 10 \mathrm{~N} 4 \mathrm{O} 2$ \\
\hline Formula weight & 218.22 \\
\hline Temperature & $150(2) \mathrm{K}$ \\
\hline Wavelength & $0.71073 \AA$ \\
\hline Crystal system & Monoclinic \\
\hline Space group & $P 2{ }_{1} / c$ \\
\hline Unit cell dimensions & $\begin{array}{l}\mathrm{a}=11.2477(7) \AA \alpha=90^{\circ} \\
\mathrm{b}=11.6242(9) \AA \beta=92.575(5)^{\circ} \\
\mathrm{c}=15.5614(10) \AA \gamma=90^{\circ}\end{array}$ \\
\hline Volume & $2032.5(2) \AA^{3}$ \\
\hline $\mathrm{Z}, \mathrm{Z}^{\prime}$ & 8,2 \\
\hline Density (calculated) & $1.426 \mathrm{Mg} / \mathrm{m}^{3}$ \\
\hline Absorption coefficient & $0.104 \mathrm{~mm}^{-1}$ \\
\hline $\mathrm{F}(000)$ & 912 \\
\hline Crystal size & $0.380 \times 0.120 \times 0.070 \mathrm{~mm}^{3}$ \\
\hline Theta range for data collection & 1.812 to $25.347^{\circ}$ \\
\hline Index ranges & $-12 \leq \mathrm{h} \leq 13,-14 \leq \mathrm{k} \leq 12,-18 \leq 1 \leq 18$ \\
\hline Reflections collected & 9800 \\
\hline Independent reflections & $3685[\mathrm{R}(\mathrm{int})=0.0399]$ \\
\hline Completeness to theta $=25.242^{\circ}$ & $99.0 \%$ \\
\hline Absorption correction & Semi-empirical from equivalents \\
\hline Max. and min. transmission & 0.989 and 0.980 \\
\hline Refinement method & Full-matrix least-squares on $\mathrm{F}^{2}$ \\
\hline Data / restraints / parameters & 3685 / 2 / 298 \\
\hline Goodness-of-fit on $\mathrm{F}^{2}$ & 0.801 \\
\hline Final $R$ indices $[\mathrm{I}>2 \operatorname{sigma}(\mathrm{I})]$ & $\mathrm{R} 1=0.0322, \mathrm{wR} 2=0.0549$ \\
\hline $\mathrm{R}$ indices (all data) & $\mathrm{R} 1=0.0719, \mathrm{wR} 2=0.0609$ \\
\hline Extinction coefficient & none \\
\hline Largest diff. peak and hole & 0.127 and -0.145 e. $\AA^{-3}$ \\
\hline
\end{tabular}

5-pyridin-2-yl-1H-[1,2,4]triazole-3-carboxylic acid ethyl ester (Table 3) do not generate chains but instead form centrosymmetric tetramers (Fig. 5). Within these units, there are further $\mathrm{C}-\mathrm{H} \cdots \mathrm{O}$ interactions and a rather long $\mathrm{N}-\mathrm{H} \cdots \mathrm{O}$ hydrogen bond. The tetrameric units are packed in a checkerboard arrangement in the solid with further weak intermolecular interactions (Fig. 6). 


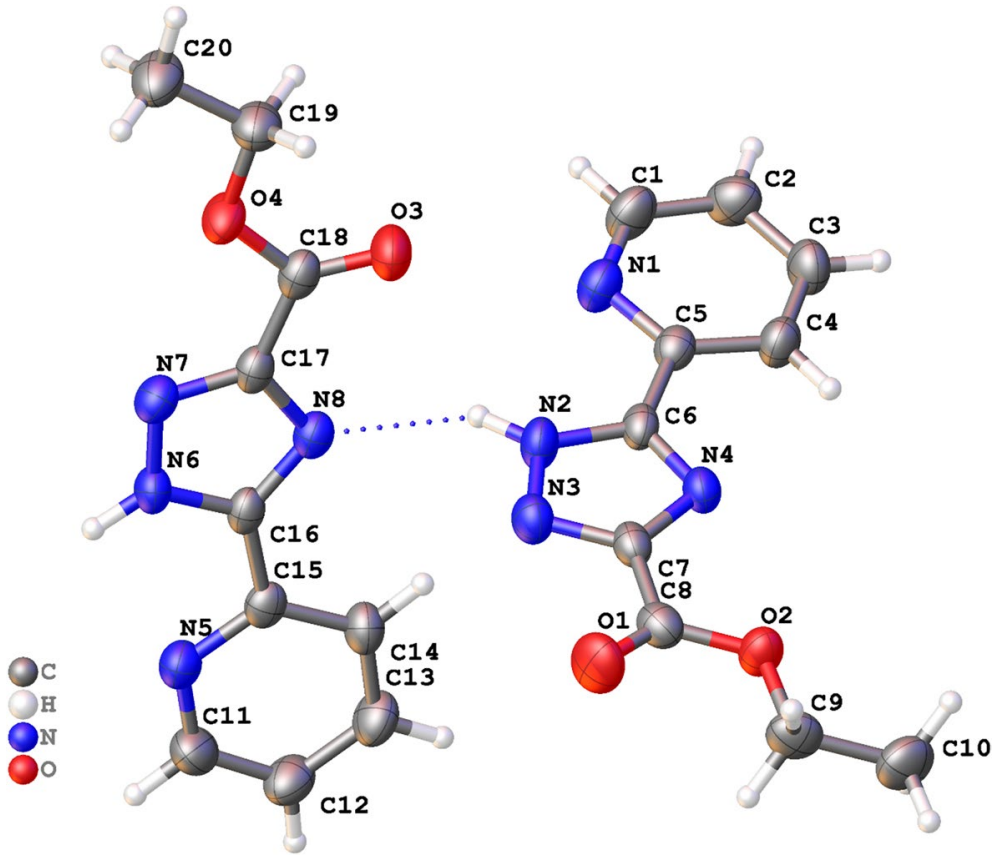

Fig. 4 Asymmetric unit of 5-Pyridin-2-yl-1H-[1,2,4]triazole-3-carboxylic acid ethyl ester with atoms drawn as $70 \%$ probability ellipsoids. The dashed line illustrates a hydrogen bond

Table 3 Hydrogen bonds in 5-Pyridin-2-yl-1H-[1,2,4] triazole-3-carboxylic acid ethyl ester (symmetry operators used to generate equivalent atoms: $i=x, 0.5-y, z-0.5 ; i i=-x$, $1-y, 1-z)$

\begin{tabular}{lllll}
\hline & $\mathrm{D}-\mathrm{H} / \AA$ & $\mathrm{D}^{\circ} \mathrm{H} \cdots \mathrm{A} /{ }^{\circ}$ & $\mathrm{D} \cdots \mathrm{A} / \AA$ & $\mathrm{H} \cdots \mathrm{A} / \AA$ \\
\hline $\mathrm{C} 12-\mathrm{H} 12 \cdots \mathrm{O} 1^{i}$ & 0.95 & 131 & $3.121(2)$ & 2.41 \\
$\mathrm{~N} 2-\mathrm{H} 2 \mathrm{~A} \cdots \mathrm{N} 8$ & $0.901(18)$ & $148.7(17)$ & $2.950(2)$ & $2.143(19)$ \\
$\mathrm{N} 2-\mathrm{H} 2 \mathrm{~A} \cdots \mathrm{O} 3$ & $0.901(18)$ & $123.0(14)$ & $3.1880(18)$ & $2.607(18)$ \\
$\mathrm{N} 6-\mathrm{H} 6 \mathrm{~A} \cdots \mathrm{N} 3{ }^{i i}$ & $0.906(18)$ & $155.0(16)$ & $2.9510(19)$ & $2.105(18)$ \\
\hline
\end{tabular}

\section{Anti-inflammatory and antimalarial activities}

Modified triazoles linked with carboxamides, NO-hybrids, N-substituted indole, or methacrylic acid moieties have led to anti-inflammatory molecules comparable to the reference drug indomethacin [4]. Anti-denaturation of egg albumin was chosen to evaluate the anti-inflammatory property of the synthesized 5-pyridin-2-yl-1H-[1,2,4]triazole-3-carboxylic acid ethyl ester. Denaturation of protein causes the production of autoantigens in conditions such as rheumatic arthritis, cancer, and diabetes which are conditions of inflammation [29]. The proteins are denaturized by heat, an external stress in-situ. This is a widely used, validated, sensitive, quick, and reliable in vitro technique to investigate the antiinflammatory activity of various products [30]. The synthesized triazole showed 


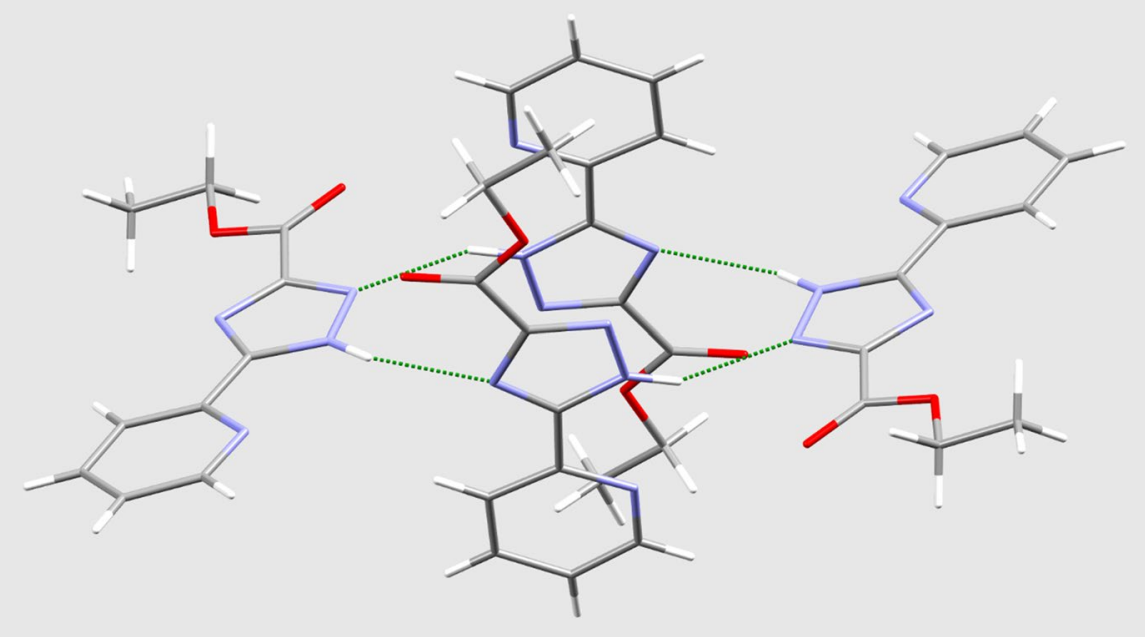

Fig. 5 Centrosymmetric hydrogen-bonded tetramer of 5-Pyridin-2-yl-1H-[1,2,4]triazole-3-carboxylic acid ethyl ester

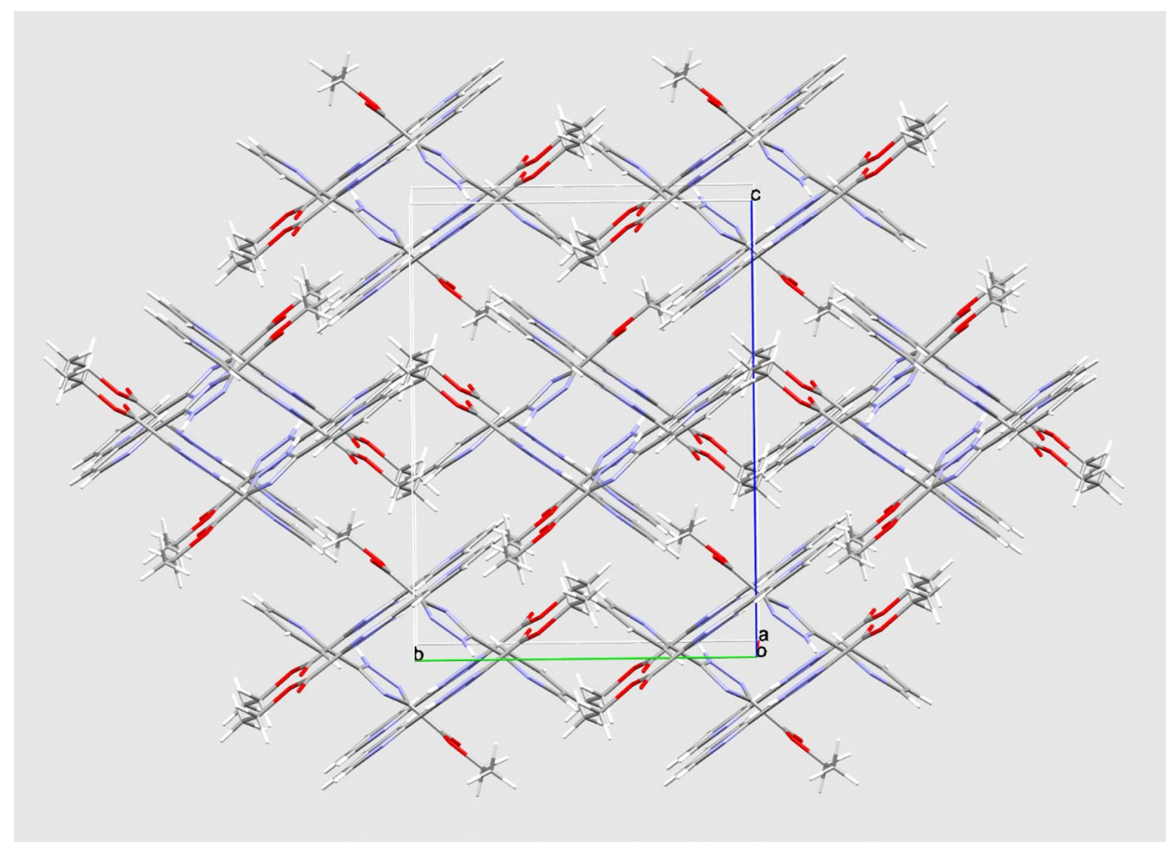

Fig. 6 Crystal packing of 5-Pyridin-2-yl-1H-[1,2,4]triazole-3-carboxylic acid ethyl ester. The view shown is just off the $y z$ plane 
Fig. 7 Histogram for comparative study between $\%$ inhibition of 5-pyridin-2-yl-1H-[1,2,4] triazole-3-carboxylic acid ethyl ester and Aspirin
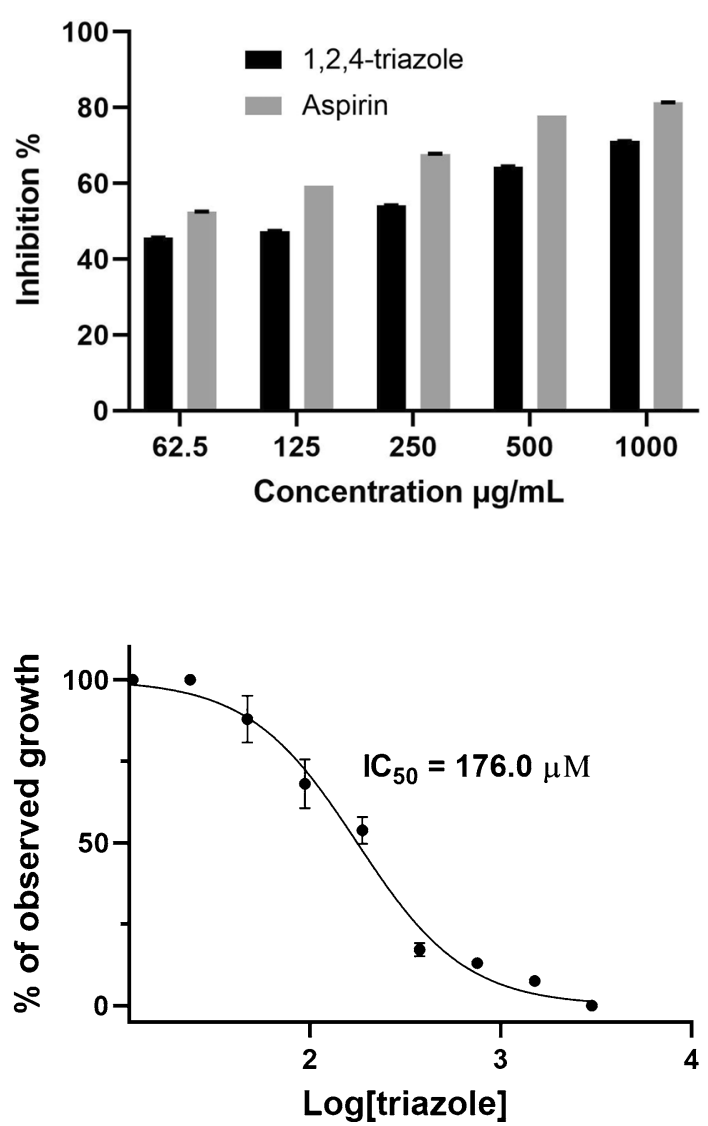

Fig. 8 SYBR green $3 \mathrm{D} 7 \mathrm{IC}_{50}$ of 5-pyridin-2-yl-1H-[1,2,4] triazole-3-carboxylic acid ethyl ester

a dose-dependent ability to inhibit thermally-induced protein denaturation with a maximal inhibition of $71.1 \%$ at $1000 \mu \mathrm{g} / \mathrm{mL}$ (Fig. 7). This effect is comparable to the standard drug Aspirin with a maximal inhibition of $81.3 \%$ at $1000 \mu \mathrm{g} / \mathrm{mL}$.

Triazole bridged antimalarial drugs have been previously reported in the literature. For example, falcipain-2 is inhibited by indoline-1,2,4-triazoles [31] and quinolone-1,2,4-triazole-imines urea derivatives show $\mathrm{IC}_{50}$ with millimolar antiplasmodial activities [32], partly due to their ability to inhibit dihydrofolate reductase [33]. A series of [1,2, 4]triazolo[1,5-a]pyrimidine derivatives exhibiting anti-P. falciparum activities were designed by Leal and co-workers [34]. In order to investigate the antimalarial potential of the synthesized triazole fragment, the SYBR green parasite viability assay measurement [35] of relative parasite levels between two parallel 3D7 cultures of the new triazole and chloroquine was carried out (Figs. 8 and 9). An $\mathrm{IC}_{50}$ value of $176 \mu \mathrm{M}$ was obtained prior to scaffold modifications by incorporation of different pharmacophoric groups at selected positions including A, B, or C in the fragment scaffold (see Scheme 1). 
Fig. 9 SYBR green 3D7 $\mathrm{IC}_{50}$ of chloroquine

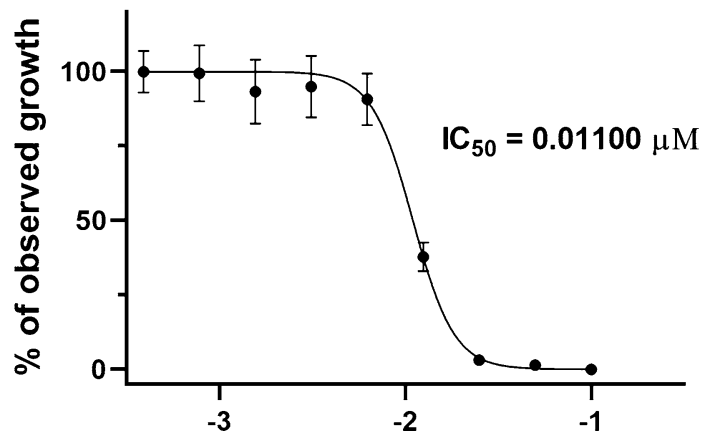

\section{Experimental section}

\section{Synthesis of 5-pyridin-2-yl-1H-[1,2,4]triazole-3-carboxylic acid ethyl ester}

Monoethyl oxalyl chloride (98\%) was supplied by Fisher Scientific Ltd. Crystals of N'-aminopyridine-2-carboximidamide were obtained according to the literature [27]. All other chemicals used were of analytical grade and used as received. To a solution of N'-aminopyridine-2-carboximidamide (1.83 g, $1.34 \mathrm{mM})$ in THF $(50 \mathrm{~mL})$ was added dropwise monoethyl oxalyl chloride $(3.05 \mathrm{~mL}, 2.69 \mathrm{mM})$. A white precipitate appeared shortly after the addition. The mixture was stirred at room temperature for 30 min under reflux. A white solid product was filtered, washed with diethyl ether, and dried in air to yield $2.80 \mathrm{~g}$ (96\%). Slow diffusion of diethyl ether into a methanolic solution of the white powder afforded crystals of 5-pyridin-2-yl-1H-[1,2,4]triazole-3-carboxylic acid ethyl ester.

\section{Spectroscopic measurements}

NMR spectra were recorded on a Jeol JNM ECP400 (400 MHz) spectrometer with $\left(\mathrm{CD}_{3}\right)_{2} \mathrm{SO} \delta_{\mathrm{H}}=2.50$ as the internal standard or residual protic solvent and $\delta_{\mathrm{C}}=30.8$ central peak for carbon-13. Chemical shifts are given in ppm $(\delta)$. Elemental analyses were performed on a Fisons EA-1108 CHNS-O Element analyser (Thermo Scientific). Fourier-transform infrared (FTIR) spectrum was recorded at room temperature as a potassium bromide pellet using a Nicolet IS5 operating at a resolution of $0.4 \mathrm{~cm}^{-1}$. Mass spectrometry was measured on a Bruker HCTultra ETD II.

\section{X-ray crystal structure determination}

Single-crystal X-ray diffraction data were collected in series of $\omega$-scans using a Stoe IPSD2 image plate diffractometer utilising monochromated Mo radiation $(\lambda=0.71073 \AA)$. Standard procedures were employed for the integration and processing of the data using X-RED [36]. Samples were coated in a thin film of perfluoropolyether oil and mounted at the tip of a glass fibre located on a goniometer. Data were collected from crystals held at $150 \mathrm{~K}$ in an Oxford cryosystems nitrogen gas cryostream. Crystal structures were solved using dual space methods implemented 
within SHELXT [37]. Completion of structures was achieved by performing least-squares refinement against all unique $\mathrm{F}^{2}$ values using SHELXL-2018 [38]. All non-H atoms were refined with anisotropic displacement parameters. Hydrogen atoms were placed using a riding model with the orientation of methyl groups allowed to refine. The positions of the hydrogen atoms attached to N2 and N6 were identified in the difference Fourier maps. These were freely refined subject to the restraint that the two $\mathrm{N}-\mathrm{H}$ distances were equal. The supplementary crystallographic data can be found in the Supporting Information or can be obtained free of charge from the Cambridge Crystallographic Data Centre via http://www.ccdc.cam.ac.uk/ data_request/cif (CCDC-2,044,682).

\section{Anti-inflammatory and antiplasmodial assays}

\section{Denaturation of egg albumin}

A reaction mixture $(5 \mathrm{~mL})$ consisting of $0.2 \mathrm{~mL}$ of egg albumin (from fresh hen's egg), $2.8 \mathrm{~mL}$ of PBS (pH 6.4), and $2 \mathrm{~mL}$ of varying concentrations of the drug (62.5, $125,250,500$, and $1000 \mu \mathrm{g} / \mathrm{mL}$ ) was incubated at $37^{\circ} \mathrm{C}$ in a biochemical oxygen demand incubator for $15 \mathrm{~min}$ and then heated at $70{ }^{\circ} \mathrm{C}$ for $5 \mathrm{~min}$. A similar volume of distilled water served as control. After cooling, their absorbance was measured at $660 \mathrm{~nm}$ by using the vehicle as blank. Aspirin at concentrations of 62.5, 125, 250, 500 , and $1000 \mu \mathrm{g} / \mathrm{mL}$ was used as reference drug and treated similarly for determination of absorbance $[39,40]$. The percentage of inhibition of protein denaturation was calculated by using Eq. 1:

$$
\% \text { inhibition }=100 \times \frac{\mathrm{Vt}}{\mathrm{Vc}-1}
$$

where $\mathrm{V}_{\mathrm{t}}$ is the absorbance of the test sample and $\mathrm{V}_{\mathrm{c}}$ is the absorbance of control.

\section{Antiplasmodial assay}

P. falciparum 3D7 strain blood-stage parasites were cultured according to standard protocols [41] at $37{ }^{\circ} \mathrm{C}, 5 \% \mathrm{CO}_{2}, 5 \% \mathrm{O}_{2}, 90 \% \mathrm{~N}_{2}$, and $80 \%$ humidity in complete RPMI medium with $0.45 \%$ (w/v) albumax II, $0.2 \mathrm{mM}$ hypoxanthine, $25 \mu \mathrm{g} / \mathrm{mL}$ gentamicin, and human A erythrocytes as previously described [42]. Synchronized 3D7 parasites were obtained after treatment with $5 \%$ sorbitol [43]. $\mathrm{IC}_{50}$ values were determined using a SYBR green I assay according to established protocols [35, 44]. Media of $1 \%$ parasitemia, $1 \%$ hematocrit cultures, and the drug was incubated for $72 \mathrm{~h}$ on 96 well plates. The plates were then wrapped with parafilm and stored overnight at $-80{ }^{\circ} \mathrm{C}$. The plates were thawed at room temperature and an aliquot $(100 \mu \mathrm{L})$ of buffered SYBR Green (Molecular Probes, Inc., Eugene, OR) was added into each culture-containing well using a multichannel Pipetman. Mixing was achieved by pipetting up and down until no cell sediment remains. The plate was wrapped in aluminium foil and stored in an incubator for $6 \mathrm{~h}$. DNA quantification was performed using a Tecan GENios microplate detection device. 


\section{Conclusion}

A new triazole 5-pyridin-2-yl-1H-[1,2,4]triazole-3-carboxylic acid ethyl ester, was synthesized as a scaffold for hybrid drug synthesis. The new molecule has been characterized and exhibits anti-inflammation and antimalarial properties. The molecule presents reaction sites that can be utilised for connection of additional pharmacophoric groups to generate new classes of hybrid molecules with enhanced therapeutic properties.

Acknowledgements FEM thanks the Commonwealth Scholarship Commission in the United Kingdom for the generous Academic Fellowship CMCF-2015-3 and the International Educational Exchange program sponsored by the U.S. government for a Fulbright African Academic Fellowship.

\section{Declarations}

Conflict of interest The authors declare that they have no known competing financial interests or personal relationships that could have appeared to influence the work reported in this paper.

\section{References}

1. P.K. Shukla, A. Verma, P. Mishra, Agriculture and human health. 1, 100 (2017)

2. B. Namratha, S.L. Gaonkar, Int. J. Pharm. Pharm. Sci. 6, 73 (2014)

3. M.A. DE S.R. Octavio, S. DE M.E.M. Leandro. An. Acad. Bras. Ciênc. 91 (2019)

4. R. Aggarwal, G. Sumran. Eur. J. Med. Chem. 205, 112652 (2020)

5. R. Kharb, P.C. Sharma, M.S. Yar, J. Enzyme Inhib. Med. Chem. 26, 1 (2011)

6. A. Diaz-Ortiz, P. Prieto, J.R. Carrillo, R. Martin, I. Torres, Curr. Org. Chem. 19, 568 (2015)

7. S. Kumar, S.L. Khokra, A. Yadav, Future. J. Pharm. Sci. 7, 1 (2021)

8. A.A. Aly, A.A. Hassan, M.M. Makhlouf, S. Bräse, Molecules 25, 1 (2020)

9. L.R. Peyton, S. Gallagher, M. Hashemzadeh, Drugs Today. 51, 705 (2015)

10. C.-H. Zhou, Y. Wang, Curr. Med. Chem. 19, 239 (2012)

11. M. Hanif, M. Saleem, M.T. Hussain, N.H. Rama, S. Zaib, M.A.M. Aslam, P.G. Jones, J. Iqbal, J. Braz. Chem. Soc. 23, 854 (2012)

12. S.N. Yunusova, D.S. Bolotin, V.V. Suslonov, M.A. Vovk, P.M. Tolstoy, V.Y. Kukushkin, ACS Omega 3, 7224 (2018)

13. E. Bokor, A. Fekete, G. Varga, B. Szocs, K. Czifrak, I. Komaromi, L. Somsak, Tetrahedron 69, 10391 (2013)

14. D. Lednicer, The Organic Chemistry of Drug Synthesis (Wiley-Intersciences, New York, 1998)

15. M. Baumann, I.R. Baxendale, Beilstein. J. Org. Chem. 9, 2265 (2013)

16. C. Chen, Y. Liu, C. Xi, Tetn. Letts. 50, 5434 (2009)

17. A. Fürstner, A. Hupperts, G. Seidel. Org. Synth. 10, 382 (2004) 76, 142 (1999)

18. P. Bradley, P. Sampson, A.J. Seed, Liq. Cryst. Today. 14, 15 (2005)

19. I. Yavari, O. Khaledian, Chem. Commun. 56, 9150 (2020)

20. R.A. Haggam, Res. Chem. Intermed. 41, 1135 (2015)

21. R.A. Haggam, Res. Chem. Intermed. 42, 7313 (2016)

22. R.A. Haggam, Res. Chem. Intermed. 47, 3733 (2021)

23. Z. Shahnavaz, N.G. Khaligh, T. Mihankhah, M.R. Johan, Res. Chem. Intermed. 46, 4645 (2020)

24. N. Rezki, M.M. Mayaba, F.F. Al-blewi, M.R. Aouad, E.S.H.E. Ashry, Res. Chem. Intermed. 43, 995 (2017)

25. B. Namratha, D. Bilehal, V. ShyamKumar, S.L. Gaonkar, Res. Chem. Intermed. 42, 1885 (2016)

26. K.R. Jaisankar, K. Kumaran, S.R.M. Kamil, T. Srinivasan, Res. Chem. Intermed. 41, 1975 (2015)

27. F. Eya'ane Meva, T.J. Prior, D.J. Evans, E.R. Mang. Acta Cryst. E73, 1021 (2017) 
28. T. Rüffer, B. Bräuer, F. Eya'ane Meva, B. Walfort. Dalton Trans. 5089 (2008)

29. S. Dharmadeva, L.S. Galgamuwa, C. Prasadinie, N. Kumarasinghe, Ayu. 39, 239 (2018)

30. W. Peters, Chemotherapy and Drug Resistance in Malaria (Academic Press, London, 1970)

31. F. Shah, J. Gut, J. Legac, D. Shivakumar, W. Sherman, P.J. Rosenthal, M.A. Avery, J. Chem. Inf. Model. 52, 696 (2012)

32. Y. Kurasawa, K. Yoshida, N. Yamazaki, E. Kaji, K. Sasaki, Y. Zamami, M. Zhao, A. Togi, H. Ito, E. Kaji, H. Fukaya, J. Heterocycl. Chem. 51, E249 (2014)

33. G. Rastelli, S. Pacchioni, W. Sirawaraporn, R. Sirawaraporn, M.D. Parenti, A.M. Ferrari, J. Med. Chem. 46, 2834 (2003)

34. B. Leal, I.F. Afonso, C.R. Rodrigues, P.A. Abreu, R. Garrett, L.C.S. Pinheiro, A.R. Azevedo, J.C. Borges, P.F. Vegi, C.C.C. Santos, F.C.A. da Silveira, L.M. Cabral, I.C.P.P. Frugulhetti, A.M.R. Bernardino, D.O. Santos, H.C. Castro, Bioorg. Med. Chem. 16, 8196 (2008)

35. M. Smilkstein, N. Sriwilaijaroen, J.X. Kelly, P. Wilairat, M. Riscoe, Antimicrob. Agents Chemother. 8, 1803 (2004)

36. X-AREA v 1.64, STOE \& Cie GmbH (Darmstadt, 2012)

37. G.M. Sheldrick, SHELXT. Acta Cryst. A71, 3 (2015)

38. G.M. Sheldrick, Acta Cryst. C71, 3 (2015)

39. P. Dey, P. Chatterjee, S. Chandra, S. Bhattacharya, J. Adv. Pharm. Technol. Res. 1, 271 (2011)

40. S. Chandra, P. Chatterjee, P. Dey, S. Bhattacharya, Pharmacognosy J. 4, 47 (2012)

41. W. Trager, J.B. Jensen, Science 193, 673 (1976)

42. C.A. Wezena, M. Urscher, R. Vince, S.S. More, M. Deponte, Redox Biol. 8, 353 (2016)

43. C. Lambros, J.P. Vanderberg, J. Parasitol. 65, 418 (1979)

44. D.J. Bacon, C. Latour, C. Lucas, O. Colina, P. Ringwald, S. Picot, Antimicrob. Agents Chemother. 51, 1172 (2007)

Publisher's Note Springer Nature remains neutral with regard to jurisdictional claims in published maps and institutional affiliations. 